Citation: Dolas, H, Sayinli, B , Sarac, A . "A Determination Method of Dopamine or Epinephrine by Conducting Polymers : The Electrochemical Impedance Spectroscopy". Journal of Engineering Technology and Applied Sciences 1 (2) $2016: 89-106$

\title{
A DETERMINATION METHOD OF DOPAMINE OR EPINEPHRINE BY CONDUCTING POLYMERS: THE ELECTROCHEMICAL IMPEDANCE SPECTROSCOPY
}

\author{
Hacer Dolas*1, Burcu Sayinli², and A.Sezai Sarac ${ }^{2}$ \\ ${ }^{* 1}$ Department of Chemistry,Art and Science of Faculty, Work Healty and Safety Programme at \\ Vocational School of Hilvan, Harran University, 63900, Sanliurfa, Turkey, \\ hacerdolas@hotmail.com \\ ${ }^{2}$ Department of Chemistry, Polymer Science and Technology, Istanbul Technical University, Maslak \\ 34469, Istanbul, Turkey, \\ sarac@itu.edu.tr, \\ burcusayinli@windowslive.com
}

\begin{abstract}
In this study, it was reported that the preparation and characterization of capacitive sensor based on conducting polymer for detection of dopamine and/or epinephrine by impedimetric method, electrochemical impedance spectroscopy. Pt electrodes coated with poly $(\mathrm{Cz})$ and poly $(\mathrm{In})$ in different electrolyte solution by electropolymerization. $\mathrm{NaClO} 4-\mathrm{ACN}$ electrolyte solution was selected as suitable electrolyte solution, due to high capacitive behavior. The usage of EIS technique for the determination of DA or EP in presence of AA was investigated. For this reason, the measurement EIS of prepared polymer coated electrodes in suitable conditions was performed by immersed in different concentrations (from $10^{-9} \mathrm{M}$ to $10^{-6} \mathrm{M}$ ) of DA or EP in presence of $10^{-4} \mathrm{M}$ of AA at $\mathrm{pH} 7$. It was found that Poly $(\mathrm{Cz})$ coated electrode was a more convenient biosensor for determination of EP by EIS method than Poly(In) and for DA determination. Also, the EIS method was able to use as the readout of Poly $(\mathrm{Cz})$ coated electrode as a biosensor for the determination of EP.
\end{abstract}

Keywords: Electro polymerization, Determination, Dopamine, Epinephrine and Impedance.

\section{Introduction}

Dopamine (DA) is one of the most crucial catecholamine neurotransmitters. It plays a significant role in contacting the nervous system. So, its deficiency in biological fluids may lead to several diseases and neurological disorders such as Schizophrenia and Parkinson's disease[1]. 
Also, Epinephrine (EP) belongs to group of substances known as catecholamine neurotransmitters which include norepinephrine and dopamine $[2,3]$. Changes in concentration of EP in the body can result in many diseases such as Alzheimer's disease and aging effect[4]. DA and EP exist for message transfer in the mammalian central nervous system (CNS) and body fluids as organic cations and always coexist with ascorbic acid (AA) in biological systems. Therefore, it is very important to develop sensitive sensor or method for the determination of DA and EP not only for biomedical chemistry and neurochemistry but also for diagnostic and pathological researches.

Various analytical methods such as the liquid chromatography, mass spectrometry [5], gas chromatography [6] and capillary electrophoresis mass spectrometry method [7] have been developed to detect these analytes. These methods require several derivatization procedures which lead time consuming and are very expensive. Because of that DA and EP are electroactive compounds; electrochemical technics for their detection have received intense interest. Unfortunately, it is known that the oxidation peaks of DA and AA are at nearly same potential with a bare electrode, which results in the overlapped voltametric responses that make their discrimination very difficult. For this reason it is important to fabricate sensitive, specific and selective biosensors that would discriminately detect DA and EP in the presence of ascorbic acid. It can be given that Poly(folic acid) on carbon paste electrode [8], graphene modified electrode [9, 10], CNT-Au nanocomposite modified electrode [11], Pt/ionic liquid/graphene nanocomposite [12], graphene/size-selected Pt nanocomposite [13] poly[NVinyl Carbazole] Formed on Carbon-Fiber Microelectrodes [14, 15], N-VinylcarbazoleAcrylamide Copolymer Electrodes [16] are examples for biosensors that prepared to detect DA.

Electrochemical impedance spectroscopy (EIS) is powerful techniques that can provide information about charge transfer and ionic transfer processes within the film. A symmetrical configuration metal/polymer/metal can provide information about electronic transport. On the other hand the symmetrical configuration solution/polymer/solution provides information about the ionic transport. The asymmetrical configuration metal/polymer/solution provides information about both phenomena; electronic and ionic transport.

EIS has become an efficient method used for many chemical and physical processes. The method presents analytical solutions for many processes. Besides these, identification of membranes, and biosensor characterization and fabrication could also be effectively monitored by EIS. Conversely, enzyme-substrate interactions, after antigen-antibody, receptor-ligand, or DNA-DNA interactions which have no catalytic reaction could be successively monitored by EIS [17-19].

In a study which was prepared biosensor based on conducting polymer to determine dopamine[10], graphene modified electrode was used for selective detection of dopamine and the change of charge transfer resistance depended on dopamine concentration was also analyzed by electrochemical impedance spectroscopy. The observed linear range for the determination of dopamine concentration was from 4 microM to 100 microM. The detection limit was estimated to be 2.64 microM.

Also EIS method was used to analyze vascular endothelial growth factor (VEGF), which was a potent biomarker of breast cancer [20]. 
In a study which hollow gold nanospheres (HGN) were fabricated based on the displacement reaction between the $\mathrm{Co}$ nanoparticles and $\mathrm{HAuCl}_{4}$ for DNA biosensor fabrication, The Nyquist plot values obtained by using electrochemical impedance spectroscopy (EIS) method were used to evaluation for the fabricated DNA biosensor [21].

In another study $\mathrm{NH}_{2}$-riched second-generation poly(amidoamine) dendrimer was covalently attached onto carbon nanotube electronic transducers to serve as the tether for surface confinement of probe DNA in solution. The hybridization of surface-tethered probe DNA with its complementary target DNA in solution, the interfacial charge-transfer resistance is increased. This increase in the charge-transfer resistance can be used as the readout of the biosensor [22].

In this study, it is aimed to show that the determination of the DA or EP can be monitored by using conducting polymer based on biosensor and electrochemical impedance spectroscopy which is fast, sensitive, and practical. For this reason, two biosensor electrodes were prepared by electrocoating $\mathrm{Pt}$ electrode with Carbazole $(\mathrm{Cz})$ or Indole (In) monomers as their corresponding polymer, separately. The potentials of the electrodes on determination of the DA or EP were compared with terms of charge transfer resistance and capacitance by using EIS.

\section{Experimental section}

\subsection{Chemical materials}

During experimental process, used chemicals as monomers were carbazole $(\mathrm{Cz})$ and indole (In) both of which purchase from Fluka. Acetonitrile (ACN) purchased from Sigma Aldrich was used as a solvent. Sodium perchlorate $\left(\mathrm{NaClO}_{4}\right)$, tetra ethyl ammonium tetra fluoro borate $\left[\left(\mathrm{C}_{2} \mathrm{H}_{5}\right)_{4} \mathrm{BF}_{4}\right]$, tetra ethyl hexafloro phosphate $\left[\left(\mathrm{C}_{2} \mathrm{H}_{5}\right)_{4}\left(\mathrm{PF}_{6}\right)\right]$, potassium perchlorate $\left(\mathrm{KClO}_{4}\right)$ were used as electrolyte. Used neurotransmitter agents were Dopamine (DA) and Epinephrine (EP) both of which purchased from Sigma Aldrich. Ascorbic Acid (AA) was purchased from Fluka. Finally, used phosphate buffer solution $\mathrm{pH} 7.0$ was purchased from Hanna Instruments.

\subsection{Electropolymerization}

The platinum $(\mathrm{Pt})$ electrode was electrocoated by using a potentiostat; the model was Princeton Applied Research, Parstat 2263. Electrochemical analyses were practiced in triplet electrode system. The system was consisted of an Ag wire as reference electrode and two Pt wires one of them is working electrode and the other one is counter electrode.

\subsection{Electrochemical impedance spectroscopy (EIS)}

The potentiostat, model Princeton Applied Research, Parstat 2263, and relevant program, PowerSuit, were put account to take electrochemical impedance measurements. These measurements were received at the room temperature $\left(25^{\circ} \mathrm{C}\right)$ by using the triplet electrode system consisting of an Ag wire electrode as reference electrode, an electrocoated electrode as working electrode, and a platinum wire electrode as a counter electrode. Each of measurements was obtained from the same frequency interval from $0.1 \mathrm{~Hz}$ to $100 \mathrm{kHz}$ and same electrolyte solution which is $\mathrm{NaClO}_{4}-\mathrm{ACN}$. 
Firstly, the convenient conditions were investigated to prepare the electrode sensing dopamine and/or epinephrine. For this reason selected two monomers (carbazole and indole) were polymerized via electrochemical polymerization in various electrolyte solutions, separately. Used the electrolyte solutions were $\left(\mathrm{C}_{2} \mathrm{H}_{5}\right)_{4} \mathrm{BF}_{4}-\mathrm{ACN}, \mathrm{KClO}_{4}-\mathrm{ACN}, \mathrm{NaClO}_{4}-\mathrm{ACN}$, and $\left(\mathrm{C}_{2} \mathrm{H}_{5}\right)_{4}\left(\mathrm{PF}_{6}\right)-\mathrm{PC}$. After electropolymerization, electrochemical impedance spectroscopic measurements were performed for each electrocoated electrode (different 8 electrodes), separately. Ultimately, electrochemical impedance results were compared among different 8 electrodes. Consequently, the most convenient electrolyte solution was selected for both carbazole and indole monomers in order to detect dopamine and epinephrine neurotransmitters.

\section{Result and discussion:}

\subsection{Preparing of the electrode coated with polycarbazole}

Pt electrode was electrocoated in $5 \cdot 10^{-3} \mathrm{M} \mathrm{Cz}$ included $0.1 \mathrm{M}$ electrolyte solution by using Cyclic Voltammeter-CV method with the scan rate $50 \mathrm{mV} / \mathrm{s}$, applying potential from $-0.1 \mathrm{~V}$ to $1.6 \mathrm{~V}$, and this process went on during 10 cycles. Figure 1 gives the cyclic voltammogram of polycarbazole $[$ poly $(\mathrm{Cz})]$ growth on the electrode.

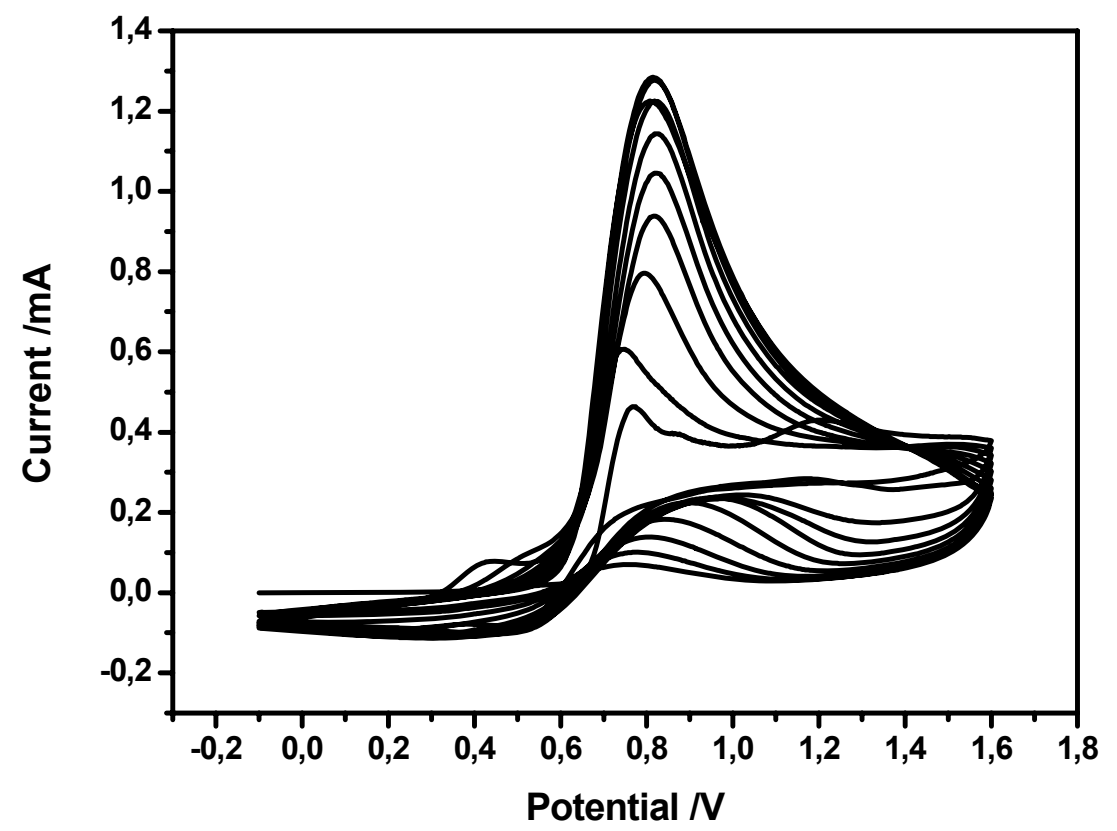

Figure 1.The cyclic voltammogram of poly $(\mathrm{Cz})$ growth on the Pt electrode. Scan rate $50 \mathrm{mV} / \mathrm{s}$, applying potential from $-0.1 \mathrm{~V}$ to $1.6 \mathrm{~V}$, cycle number 10 .

The monomer oxidized at $0.60 \mathrm{~V}$ and reduced at $0.54 \mathrm{~V}$ (Fig. 1). The formation of poly $(\mathrm{Cz})$ was observed on the surface of electrode, successfully.

\subsection{Preparing of the electrode coated with Polyindole}

Polyindole [poly(In)] coated electrode was prepared in $0.1 \mathrm{M}$ indole included in $5 \mathrm{~mL}$ of $0.1 \mathrm{M}$ electrolyte solution in electrochemical cell. Applied conditions were the scan rate $100 \mathrm{mV} / \mathrm{s}$, 
applying potential from $-0.2 \mathrm{~V}$ to $1.2 \mathrm{~V}$, and this process went on during 10 cycles. Figure 2 gives the cyclic voltammogram of poly(In) growth on the electrode.

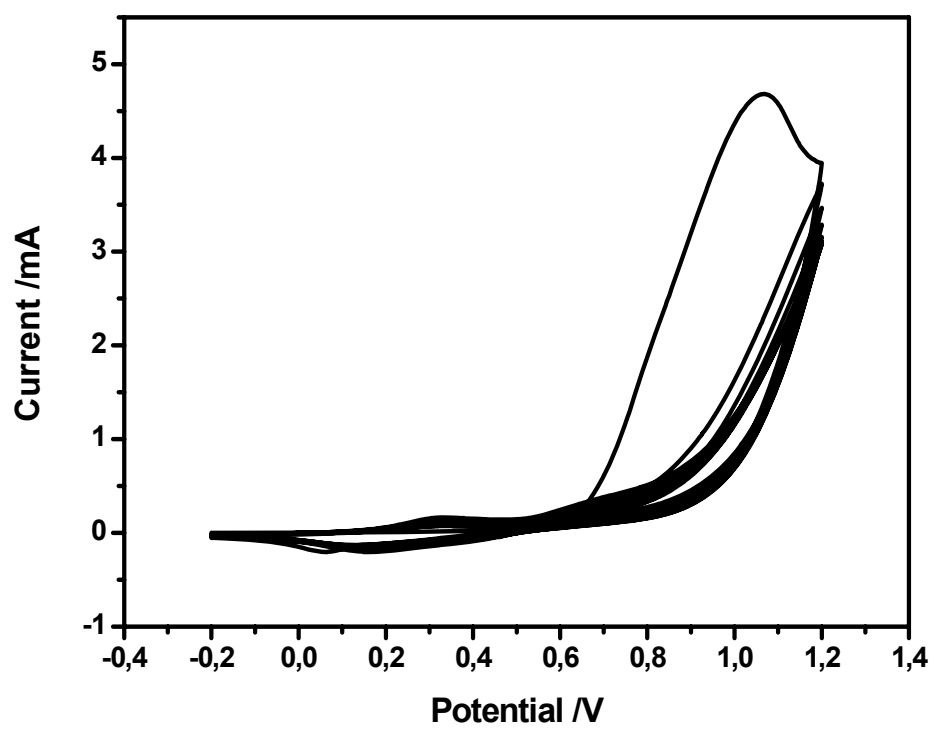

Figure 2. The cyclic voltammogram of poly(In) growth on the Pt electrode. Scan rate $100 \mathrm{mV} / \mathrm{s}$, applying potential from $-0.2 \mathrm{~V}$ to $1.2 \mathrm{~V}$, cycle number 10 .

The monomer oxidized at $0.54 \mathrm{~V}$ and reduced at $0.46 \mathrm{~V}$ (Fig 2.). The formation of poly(In) was observed on the surface of electrode, successfully.

\subsection{The EIS evaluation of the electrolyte/Poly(Cz) or poly(In)/electrode systems}

In order to investigate the electrical properties of the electrolyte/polymer/electrode system, EIS experimentals of the systems were carried out in monomer free solution. Nyquist plot, bode-phase plot, bode-magnitude plot and admittance and/or capacitance plot were obtained from EIS results. These plots, especially Nyquist plot, is given information us about the capacitive or resistive behavior of the system. So, the Nyquist graphs of prepared systems by using poly(Cz) (Fig.3a)or poly(In)(Fig.3b) were illustrated in Figure 3. 


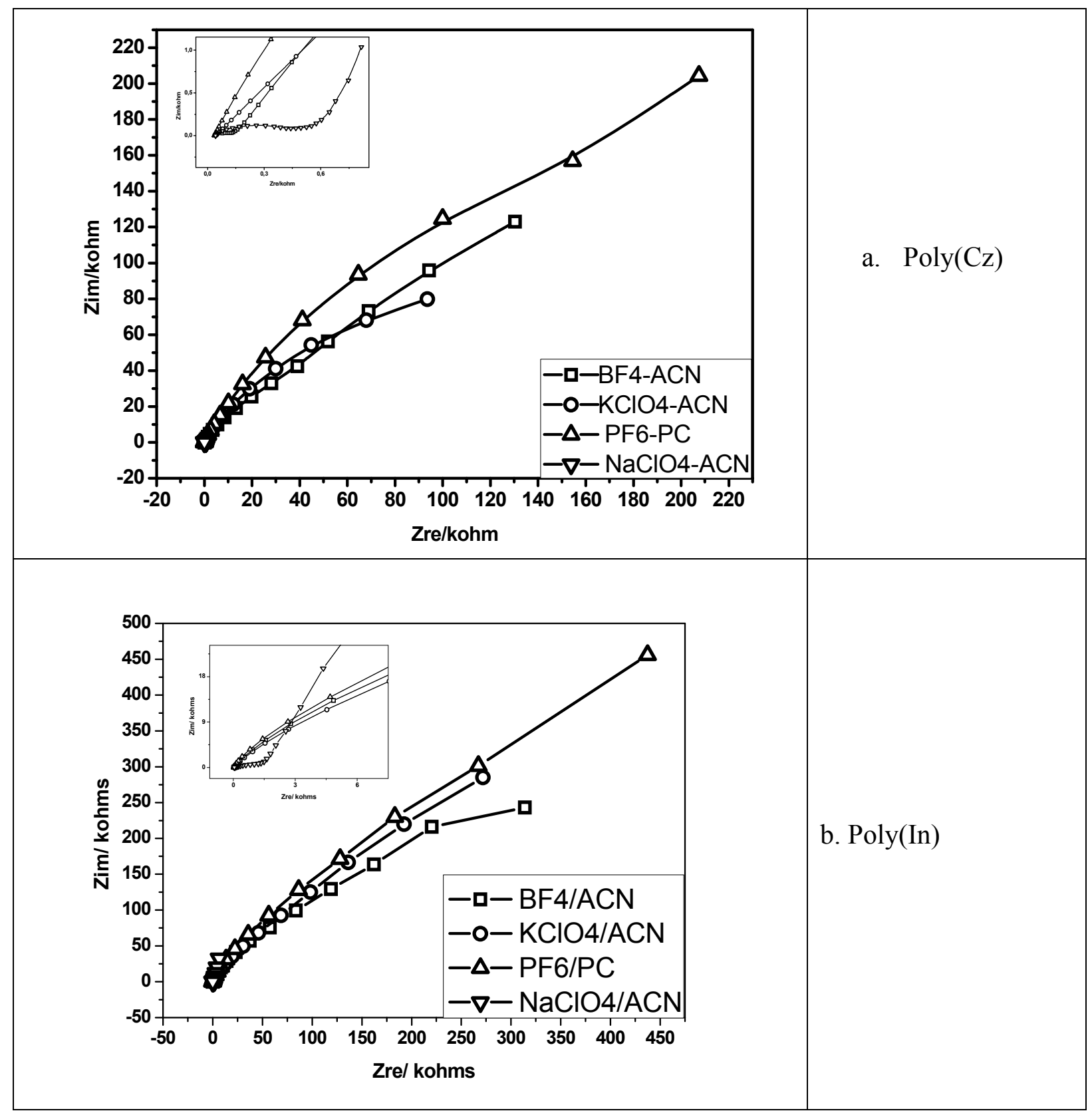

Figure3. Nyquist graphics of a) Poly $(\mathrm{Cz})$ b) Poly(In), measured in different electrolyte solution [0.1M BF $\left.4 / \mathrm{ACN}, 0.1 \mathrm{M} \mathrm{KClO}_{4} / \mathrm{ACN}, 0.1 \mathrm{M} \mathrm{PF} 6 / \mathrm{PC}, 0.1 \mathrm{M} \mathrm{NaClO}_{4} / \mathrm{ACN}\right]$.

To evaluate each electrolyte conditions, low frequency capacitance ( $\mathrm{Clf}_{\mathrm{lf}}$-Specific capacitance) value was calculated from the related Nyquist graph by using the Equation 1.[23-26].

$C_{l f}=\frac{1}{2 \pi f Z_{i m}}$

If obtained Clf's were ordered, the following range was attained.

- $\quad \mathrm{PCz}$ : $\mathrm{NaClO}_{4} / \mathrm{ACN}>\mathrm{KClO}_{4} / \mathrm{ACN}>\mathrm{BF}_{4} / \mathrm{ACN}>\mathrm{PF}_{6} / \mathrm{PC}$

- PIn : $\mathrm{NaClO}_{4} / \mathrm{ACN}>\mathrm{KClO}_{4} / \mathrm{ACN}>\mathrm{BF}_{4} / \mathrm{ACN}>\mathrm{PF}_{6} / \mathrm{PC}$ 
In this case $\mathrm{NaClO}_{4}-\mathrm{ACN}$ electrolyte medium was selected for electropolymerization of $\mathrm{Cz}$ and in because of its higher value.

Double layer capacitance $(\mathrm{Cdl})$ values were calculated by using average of $\mathrm{Z}(|\mathrm{Z}|)$ which is obtained from Bode-Magnitude plot. $\mathrm{C}_{\mathrm{dl}}$ is proportional to $1 /|Z|[23-26]$. The order of calculated $\mathrm{C}_{\mathrm{dl}}$ values is given below.

Order for double layer capacitance values $\left(\mathrm{C}_{\mathrm{dl}}\right)$

- $\mathrm{PCz}: \mathrm{NaClO}_{4} / \mathrm{ACN}>\mathrm{KClO}_{4} / \mathrm{ACN}>\mathrm{BF}_{4} / \mathrm{ACN}>\mathrm{PF}_{6} / \mathrm{PC}$

- $\quad \mathrm{PIn}: \mathrm{NaClO}_{4} / \mathrm{ACN}>\mathrm{KClO}_{4} / \mathrm{ACN}>\mathrm{BF}_{4} / \mathrm{ACN}>\mathrm{PF}_{6} / \mathrm{PC}$

So, the obtained polymers in $\mathrm{NaClO}_{4} / \mathrm{ACN}$ electrolyte medium have the higher double layer capacitance than that of other medium.

To observe the effect of different electrolyte medium on charge transfer resistance of the system, the admittance graphs belonged to poly $(\mathrm{Cz})$ and poly (In) were given in Figure 4. 


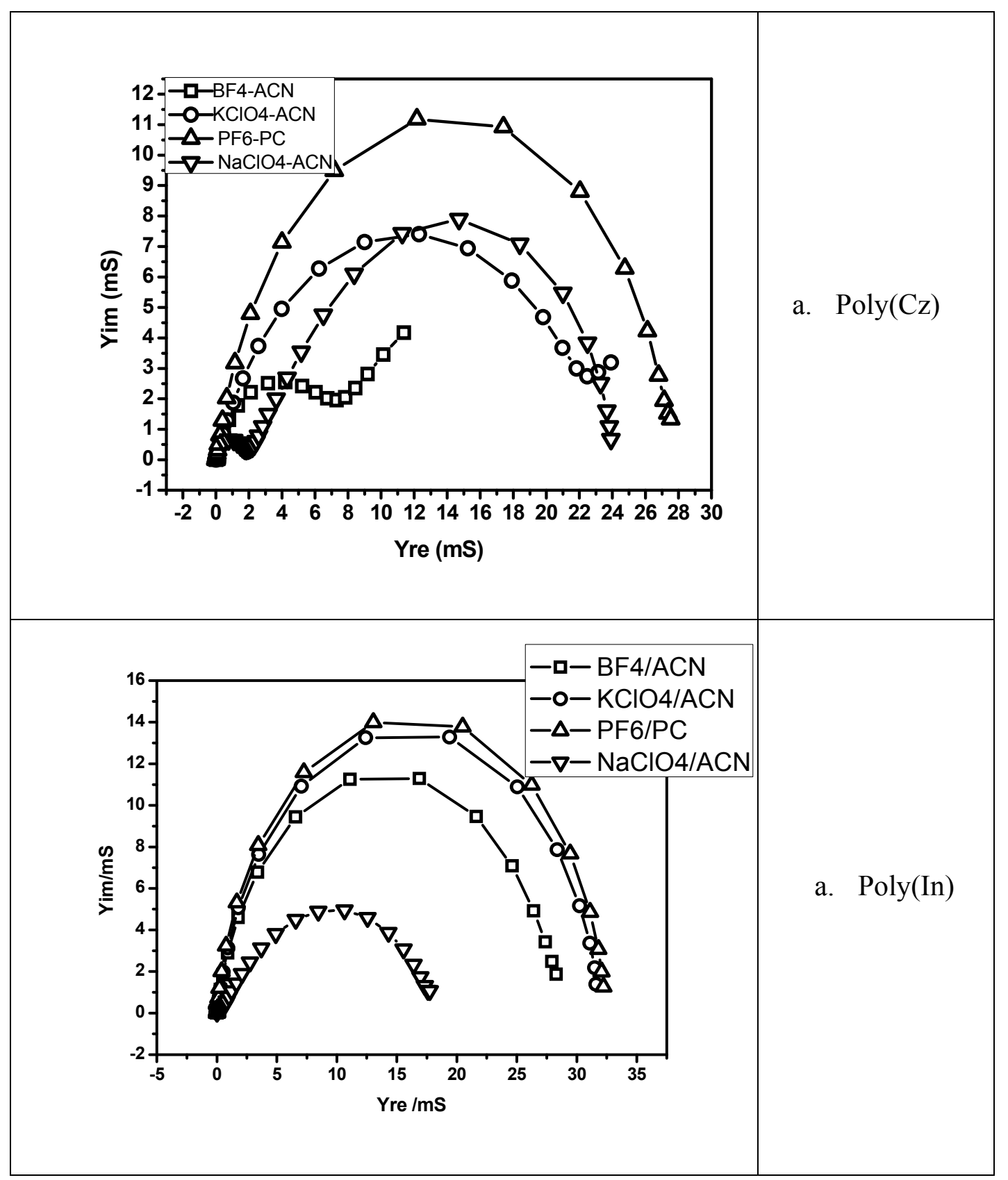

Figure 4. Admittance graphics of a) Poly $(\mathrm{Cz})$ b) Poly(In), measured in different electrolyte solution $\left[0.1 \mathrm{M} \mathrm{BF}_{4} / \mathrm{CAN}, 0.1 \mathrm{M} \mathrm{KClO}_{4} / \mathrm{CAN}, 0.1 \mathrm{M} \mathrm{PF}_{6} / \mathrm{PC}, 0.1 \mathrm{M} \mathrm{NaClO}_{4} / \mathrm{ACN}\right]$.

Order for charge transfer resistance (Rct)

- $\quad \mathrm{PCz}: \mathrm{NaClO}_{4} / \mathrm{ACN}>\mathrm{BF}_{4} / \mathrm{ACN}>\mathrm{KClO}_{4} / \mathrm{ACN}>\mathrm{PF}_{6} / \mathrm{PC}$

- $\quad \mathrm{PIn}: \mathrm{NaClO}_{4} / \mathrm{ACN}>\mathrm{BF}_{4} / \mathrm{ACN}>\mathrm{KClO}_{4} / \mathrm{ACN}>\mathrm{PF}_{6} / \mathrm{PC}$

As seen in the above order of charge transfer resistance in $\mathrm{NaClO}_{4} / \mathrm{ACN}$ electrolyte solution is higher than in the others. $\mathrm{C}_{\mathrm{lf}}$, phase angle and $\mathrm{C}_{\mathrm{dl}}$ data belong to the electrode coated with poly(Cz) and poly(In) were given in Table 1 and Table 2, separately. 
Table 1. $\mathrm{C}_{\mathrm{lf}}(\mathrm{mF})$, Phase Angle $\left({ }^{\circ}\right.$ degree $)$, and $\mathrm{C}_{\mathrm{dl}}(\mathrm{mF})$ values of electrolytes for Poly $(\mathrm{Cz})$ coated electrode.

\begin{tabular}{|c|c|c|c|}
\hline Electrolyte & $\mathbf{C}_{\mathbf{l f}} \mathbf{( m F )}$ & Phase Angle ('degree) & $\mathbf{C}_{\mathbf{d l}}(\mathbf{m F})$ \\
\hline $\mathrm{BF} 4 / \mathrm{ACN}$ & 0,13 & 43,24 & 0,0081 \\
\hline $\mathrm{KClO}_{4} / \mathrm{ACN}$ & 0,20 & 40,42 & 0,0125 \\
\hline $\mathrm{NaClO}_{4} / \mathrm{ACN}$ & 15,17 & 52,07 & 0,9520 \\
\hline $\mathrm{PF}_{6} / \mathrm{PC}$ & 0,08 & 44,65 & 0,0049 \\
\hline
\end{tabular}

Table 2. $\mathrm{C}_{\mathrm{lf}}(\mathrm{mF})$, Phase Angle $\left({ }^{\circ}\right.$ degree$)$, and $\mathrm{C}_{\mathrm{dl}}(\mathrm{mF})$ values of electrolytes for Poly $(\mathrm{In})$ coated electrode.

\begin{tabular}{|c|c|c|c|}
\hline Electrolyte & $\mathbf{C}_{\text {lf }}(\mathbf{m F})$ & Phase Angle ( ${ }^{\mathbf{0}}$ degree) & $\mathbf{C}_{\mathbf{d l}}(\mathbf{m F})$ \\
\hline $\mathrm{BF} 4 / \mathrm{ACN}$ & 0.065 & 37.65 & 0.00409 \\
\hline $\mathrm{KClO}_{4} / \mathrm{ACN}$ & 0.056 & 46.69 & 0.00351 \\
\hline $\mathrm{NaClO}_{4} / \mathrm{ACN}$ & 0.470 & 78.58 & 0.03110 \\
\hline $\mathrm{PF}_{6} / \mathrm{PC}$ & 0.035 & 46.29 & 0.00220 \\
\hline
\end{tabular}

According to obtained values, the highest $\mathrm{C}_{\mathrm{lf}}, \mathrm{C}_{\mathrm{dl}}, \mathrm{C}_{\mathrm{sp}}$, and phase angle values belong to electrocoated electrode polymerizing in $\mathrm{NaClO}_{4} / \mathrm{ACN}$ electrolyte solution. These highest values demonstrate that the most capacitive attitude is exhibited by $\mathrm{NaClO}_{4} / \mathrm{ACN}$ electrolyte. Depending on these values, it was decided that the convenient electrolyte solution for polymerizations both carbazole and indole monomers was $\mathrm{NaClO}_{4} / \mathrm{ACN}$.

\subsection{Dopamine \& epinephrine detection}

Before Dopamine (DA) and Epinephrine (EP) were detected, Carbazole or indole monomers were polymerized onto $\mathrm{Pt}$ wire by electrochemically method in $0.1 \mathrm{M} \mathrm{NaClO} / \mathrm{ACN}$ electrolyte solution. Therefore, electrode coated with Polycarbazole $(\operatorname{Poly}(\mathrm{Cz}))$ and electrode coated with polyindole (Poly(In)) were obtained. These electrodes were used as working electrode in triplet electrode system.

DA and EP solutions with 7 different concentrations $\left(10^{-9}-10^{-6} \mathrm{M}\right)$ coexisting with ascorbic acid $\left(10^{-4} \mathrm{M}\right)$ were prepared. Used buffer solution was $0.1 \mathrm{M}$ phosphate buffer solution with $\mathrm{pH}$ 7.0. Electrochemical impedance response of each of concentrations that prepared was measured from the lowest concentration to the highest by Electrochemical Impedance Spectroscopy method. 


\subsubsection{EIS Measurements for Poly $(\mathrm{Cz})$ Coated Electrode in Presence of DA \& AA}

The aim of this experiment is to detect the different concentration of Dopamine coexisting with Ascorbic Acid by EIS method. For this reason, EIS measurements were carried out by using the polymer $[\operatorname{Poly}(\mathrm{Cz})$ or Poly(In)] coated electrode in electrolyte solution having different DA or EP concentrations $\left[10^{-9} \mathrm{M}, 5.10^{-9} \mathrm{M}, 10^{-8} \mathrm{M}, 5.10^{-8} \mathrm{M}, 10^{-7} \mathrm{M}, 5.10^{-7} \mathrm{M}\right.$, and $10^{-}$ ${ }^{6} \mathrm{M}$ ] coexist with $10^{-4} \mathrm{M}$ AA. In this part, $\mathrm{PCz}-\mathrm{DA}$ system was discussed.

In Nyquist plots, the semicircle diameter at high frequencies corresponds to the electrontransfer resistance (Rct) and the linear part at lower frequencies corresponds to the diffusion process (Warburg impedance). So, Nyquist graphic demonstrates the electrical attitude at electrolyte/polymer(Pz)/electrode system. Variation in concentration of DA leads to the change of this attitude. Obtained Rct from Nyquist data (in Figure 5a inset graph) were plotted vs DA concentration in Figure 5a. The Rct value increased with the increasing of DA concentration. The increasing was clearer at lower concentrations. Figure $5 \mathrm{~b}$ illustrated the Bode Phase graph. As the phase angle increased, an electrode was more capacitive. In here, the phase angle decreased with the increasing of DA concentration. It can be contributed to the blocking of the electrode surface. 


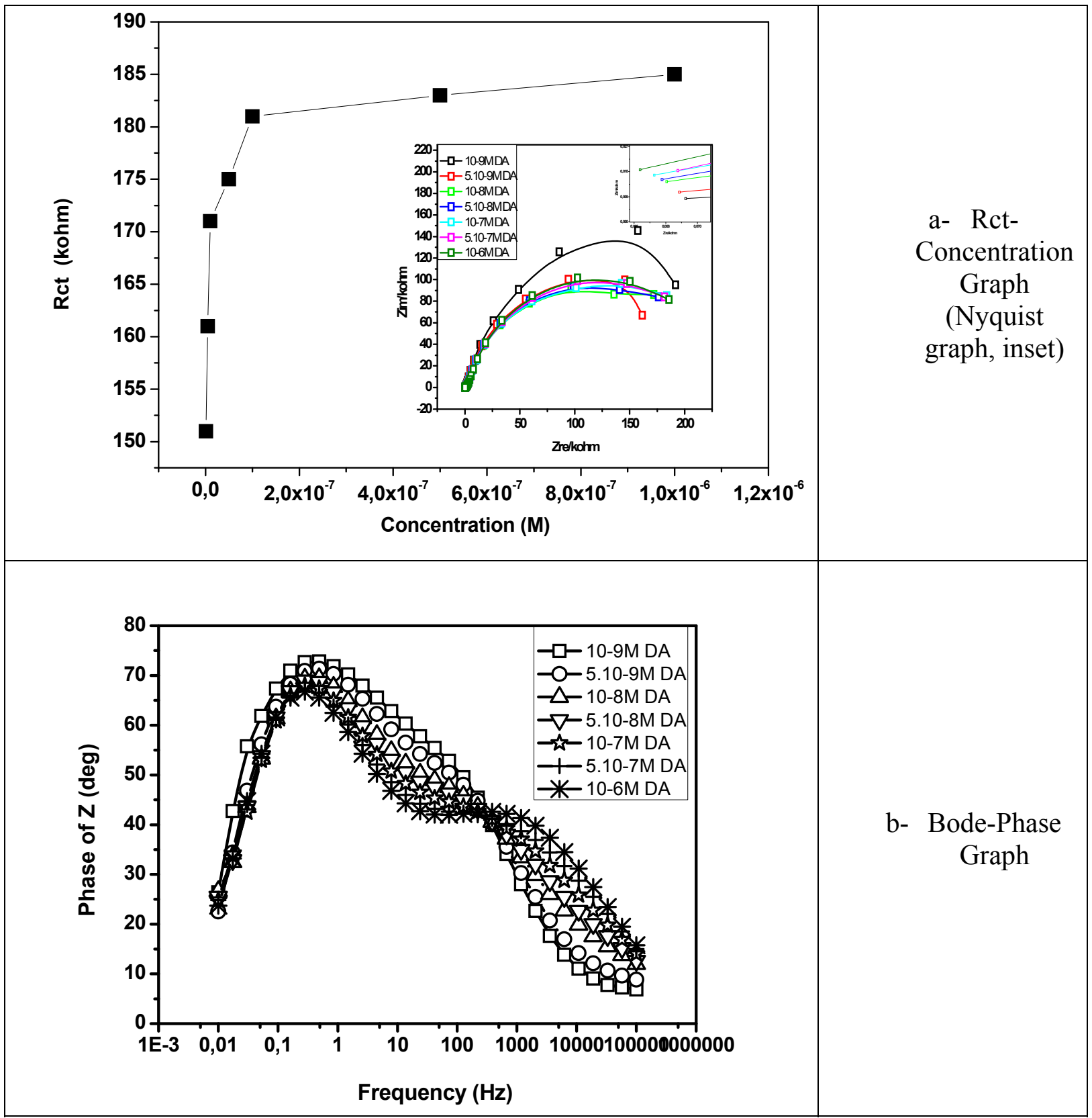

Figure 5. Nyquist graphic for Poly $(\mathrm{Cz})$ coated electrode presence of different DA concentrations $\left[10^{-}\right.$ ${ }^{9} \mathrm{M}, 5.10^{-9} \mathrm{M}, 10^{-8} \mathrm{M}, 5.10^{-8} \mathrm{M}, 10^{-7} \mathrm{M}, 5.10^{-7} \mathrm{M}$, and $\left.10^{-6} \mathrm{M}\right]$ coexist with $10^{-4} \mathrm{M}$ AA.

\subsubsection{1 eis measurements for poly (in) coated electrode in the presence of DA \& AA}

Electrochemical impedance values of the electrolyte/poly(In)/electrode system were measured by using poly(In) coated electrode. As seen from Figure 6, while concentration of DA was increased from $10^{-9} \mathrm{M}$ to $10^{-6} \mathrm{M}$, the $\mathrm{C}_{\mathrm{sp}}$ values decreased systematically (inset graph). When the graphics were overlapped in one graph, results of EIS measurement could be separated as both visual and calculating for each concentration [22]. 


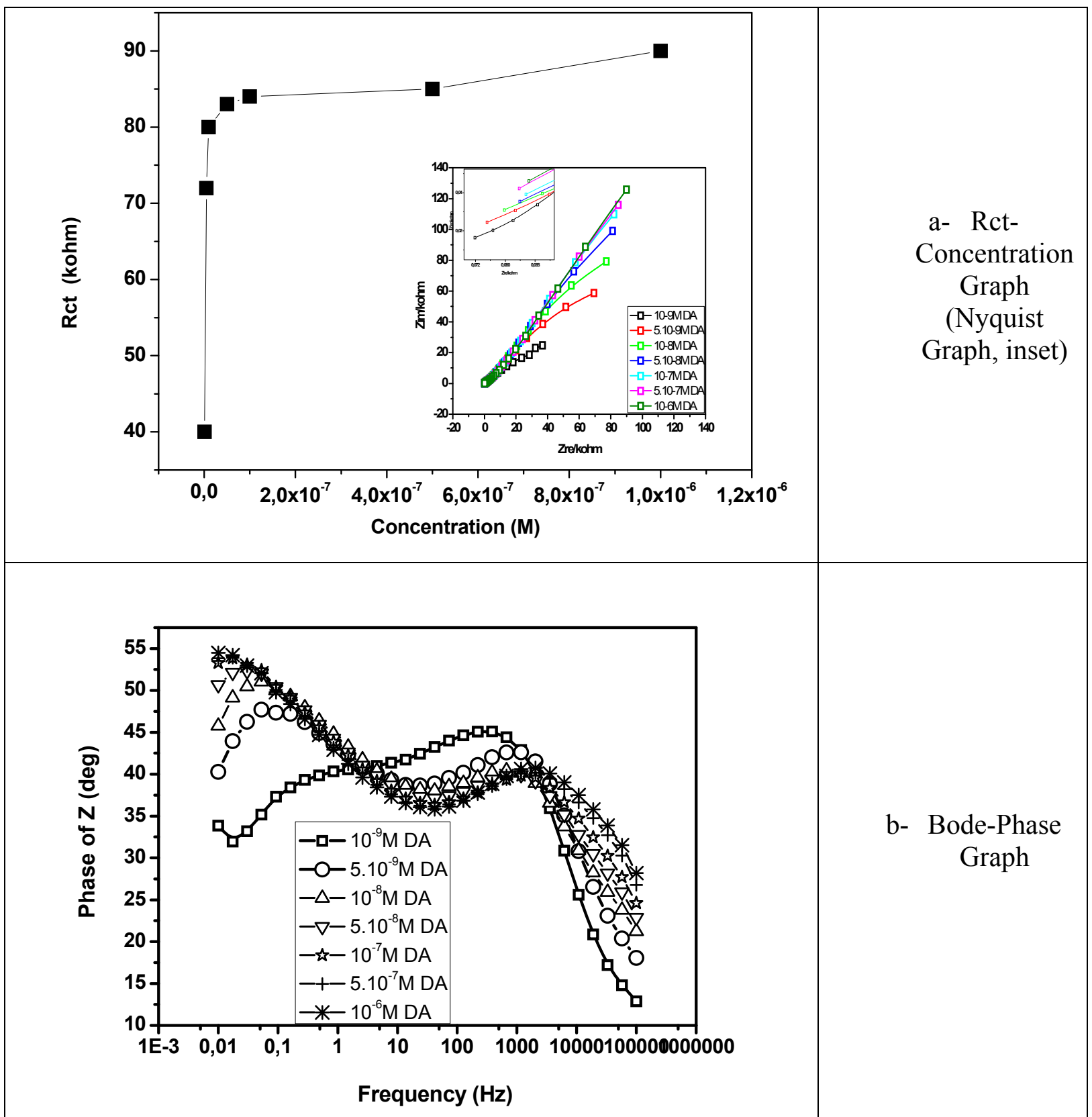

Figure 6. Rct and Bode Phase graphs for Poly(In) coated electrode presence of different DA concentrations $\left[10^{-9} \mathrm{M}, 5.10^{-9} \mathrm{M}, 10^{-8} \mathrm{M}, 5.10^{-8} \mathrm{M}, 10^{-7} \mathrm{M}, 5.10^{-7} \mathrm{M}\right.$, and $\left.10^{-6} \mathrm{M}\right]$ coexist with $10^{-}$ ${ }^{4} \mathrm{M}$ AA.

The separation was explicit especially between $10^{-9} \mathrm{M}$ to $5.10^{-8} \mathrm{M}$. However, over $5.10^{-8} \mathrm{M}$, the distinction between values belonged to the higher concentrations could be seen that it was small, clearly.

\subsubsection{EIS measurements for poly $(\mathrm{Cz})$ coated electrode presence of EP \& AA}

To investigate the Electrochemical impedance values of the electrode coated with poly $(\mathrm{Cz})$ in different concentration of EP, prepared poly $(\mathrm{Cz})$ coated electrode were immersed in $10^{-4} \mathrm{M}$ AA and different concentration of EP included solution ( $\mathrm{pH} 7)$ and EIS data were gathered via 
applied measurements. The change of charge transfer from Nyquist plot and phase angle data were given in Figure 7.

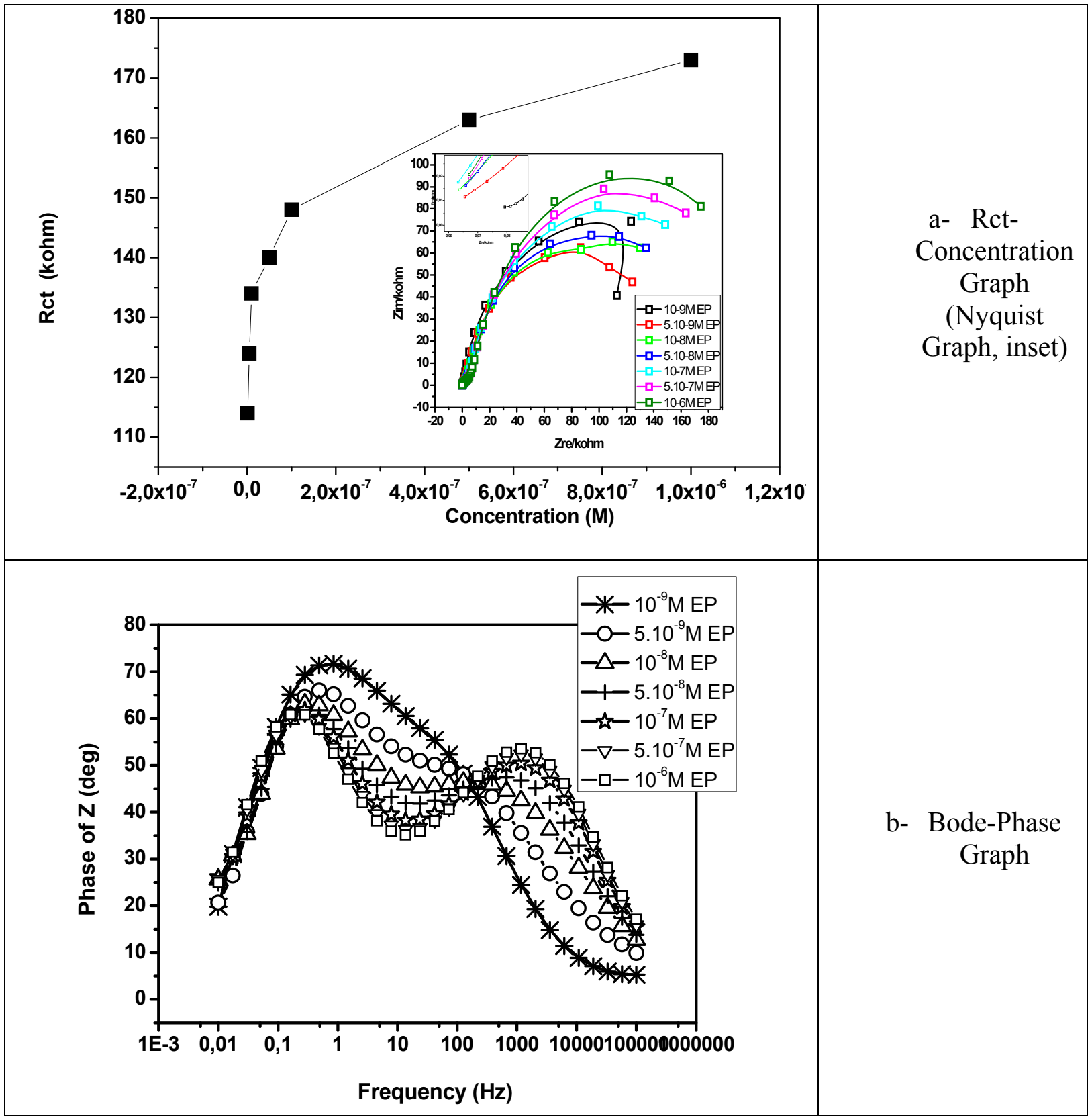

Figure7. Rct and Bode-Phase graphs for Poly $(\mathrm{Cz})$ coated electrode presence of different EP concentrations $\left[10^{-9} \mathrm{M}, 5.10^{-9} \mathrm{M}, 10^{-8} \mathrm{M}, 5.10^{-8} \mathrm{M}, 10^{-7} \mathrm{M}, 5.10^{-7} \mathrm{M}\right.$, and $\left.10^{-6} \mathrm{M}\right]$ coexist with $10^{-}$ ${ }^{4} \mathrm{M}$ AA.

As seen from the Figure, the trend of change of Rct was same, but at high concentration the distinction of Rct values were clear.

\subsubsection{EIS measurements for poly(In) coated electrode presence of EP \& AA}

While concentration of EP was increased from $10^{-9} \mathrm{M}$ to $10^{-6} \mathrm{M}$, the Rct values were increased. As expected, trend was the same with the formers. 
Figure 8 shows the gathered Rct and Bode-Phase angle data with poly(In)/electrode system.

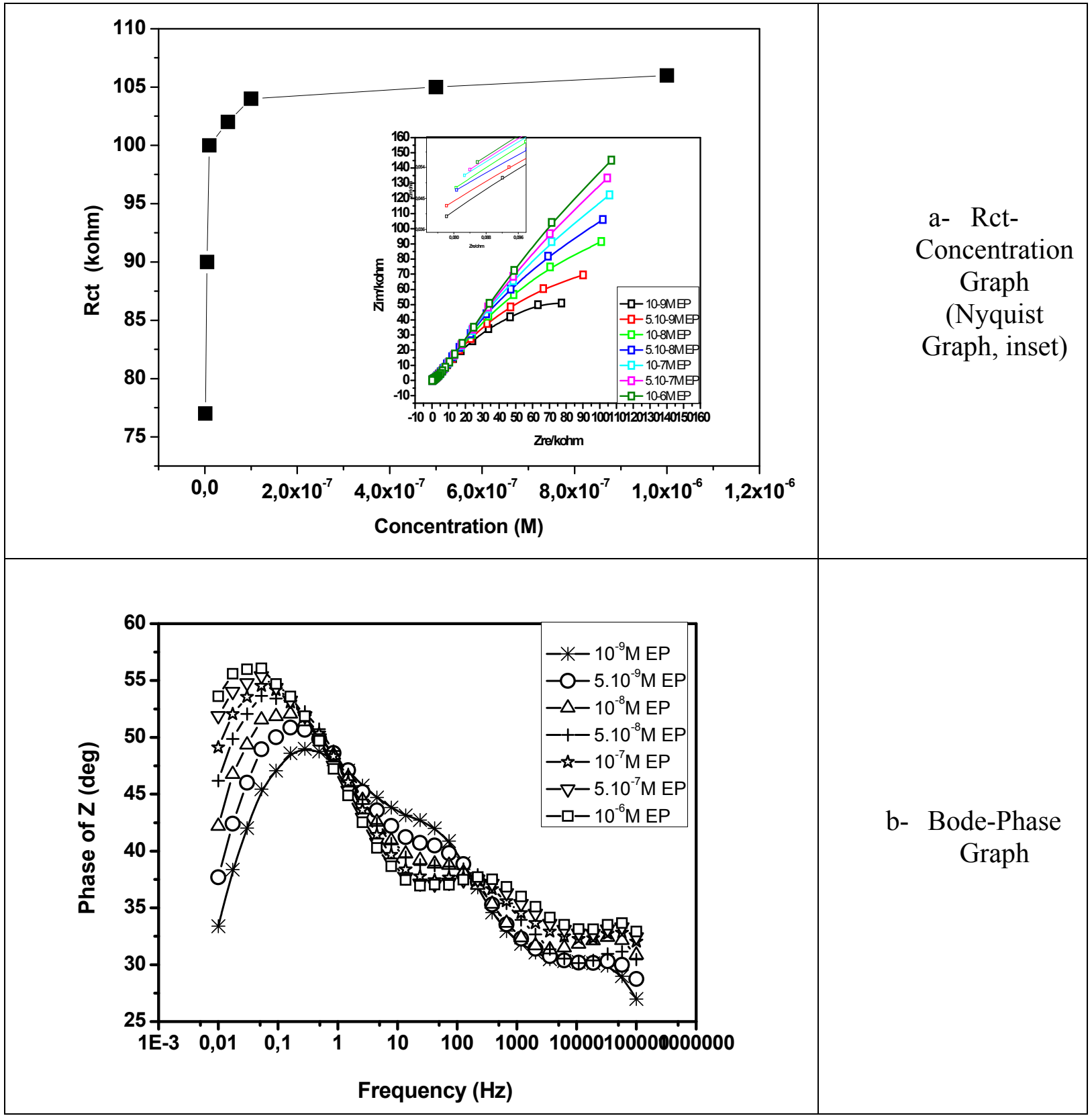

Figure8. Rct and Bode-Phase graphs for Poly(In) coated electrode presence of different EP concentrations $\left[10^{-9} \mathrm{M}, 5.10^{-9} \mathrm{M}, 10^{-8} \mathrm{M}, 5.10^{-8} \mathrm{M}, 10^{-7} \mathrm{M}, 5.10^{-7} \mathrm{M}\right.$, and $\left.10^{-6} \mathrm{M}\right]$ coexist with $10^{-}$ ${ }^{4} \mathrm{M}$ AA.

It was clear that the determination of EP can be made by using the electrode coated with poly(In), due to a net discrimination at low concentrations and frequencies, especially.

At all experiments, it was seen that the determination of DA or EP was successfully achieved at $10^{-8} \mathrm{M}$ and lower concentrations. The determination may be not clear at the higher concentrations. Surface activity may be reached equilibrium because of saturated surface pores at high concentration. 


\subsubsection{Determination of poly $(C z)$ concentration- $C_{L F}$-phase of $Z$ both $D A$ and $E P$}

In this section, EIS parameters were given comparatively. Figure 9 illustrated the change of $\mathrm{C}_{\mathrm{LF}}$ and phase angle of electrode coated with poly $(\mathrm{Cz})$ depended on the concentration of DA or EP.

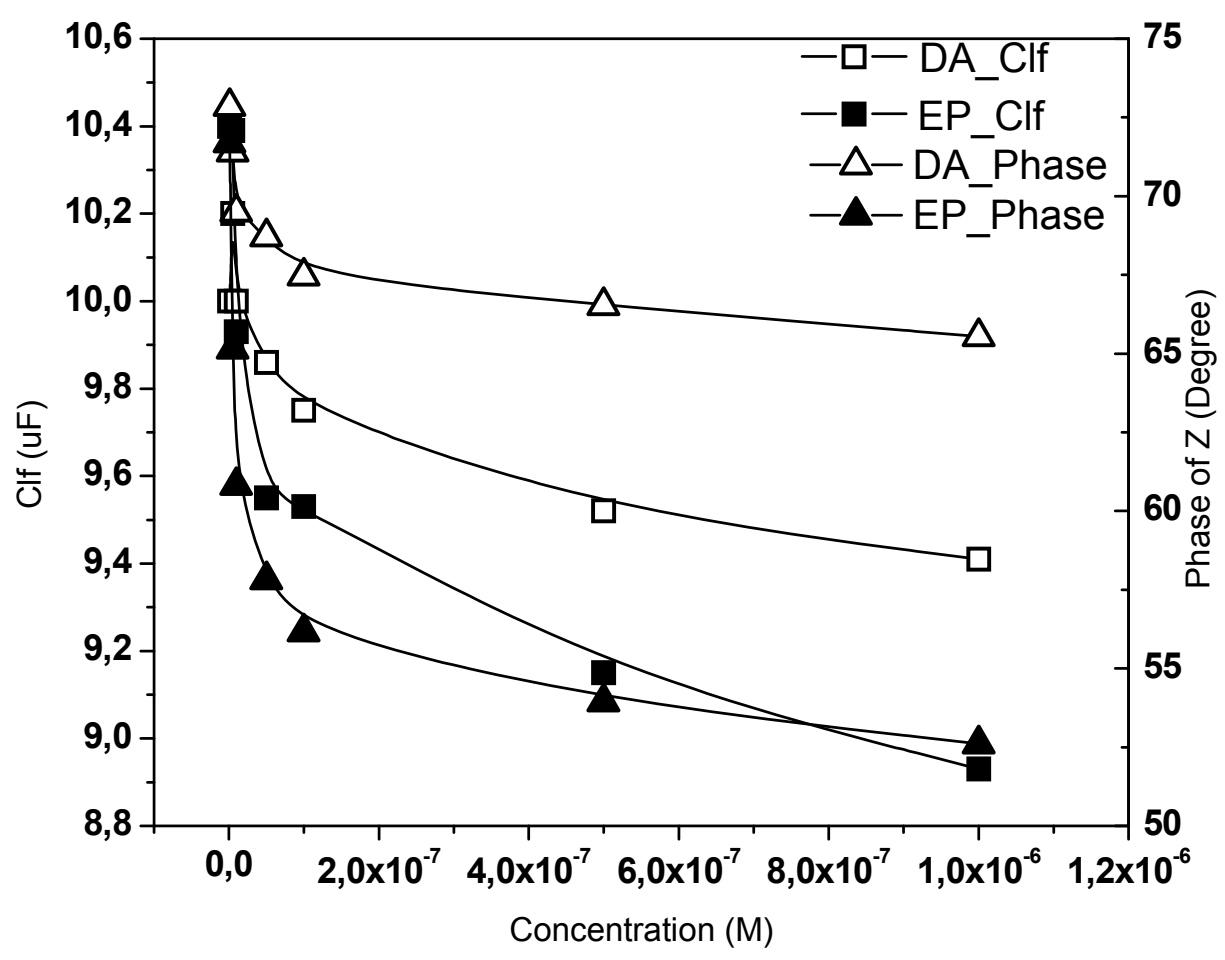

Figure 9. Graphic for Poly $(\mathrm{Cz})$ concentration-Clf-Phase of $Z$ for Both DA And EP.

As seen the figure as the concentration was increased, $\mathrm{C}_{\text {lf }}$ and Phase angle were decreased. But for EP determination, the discrimination between of concentration was clearer than that for DA, especially at low concentrations.

\subsubsection{Determination of Poly (in) concentration-Clf-Phase of $Z$ both $D A$ and $E P$}

Also, in this section $\mathrm{C}_{\mathrm{lf}}$, phase angle and $\mathrm{C}_{\mathrm{dl}}$ parameters for poly(In)/electrode system depended on the concentration of DA or EP was given in Figure 10. 


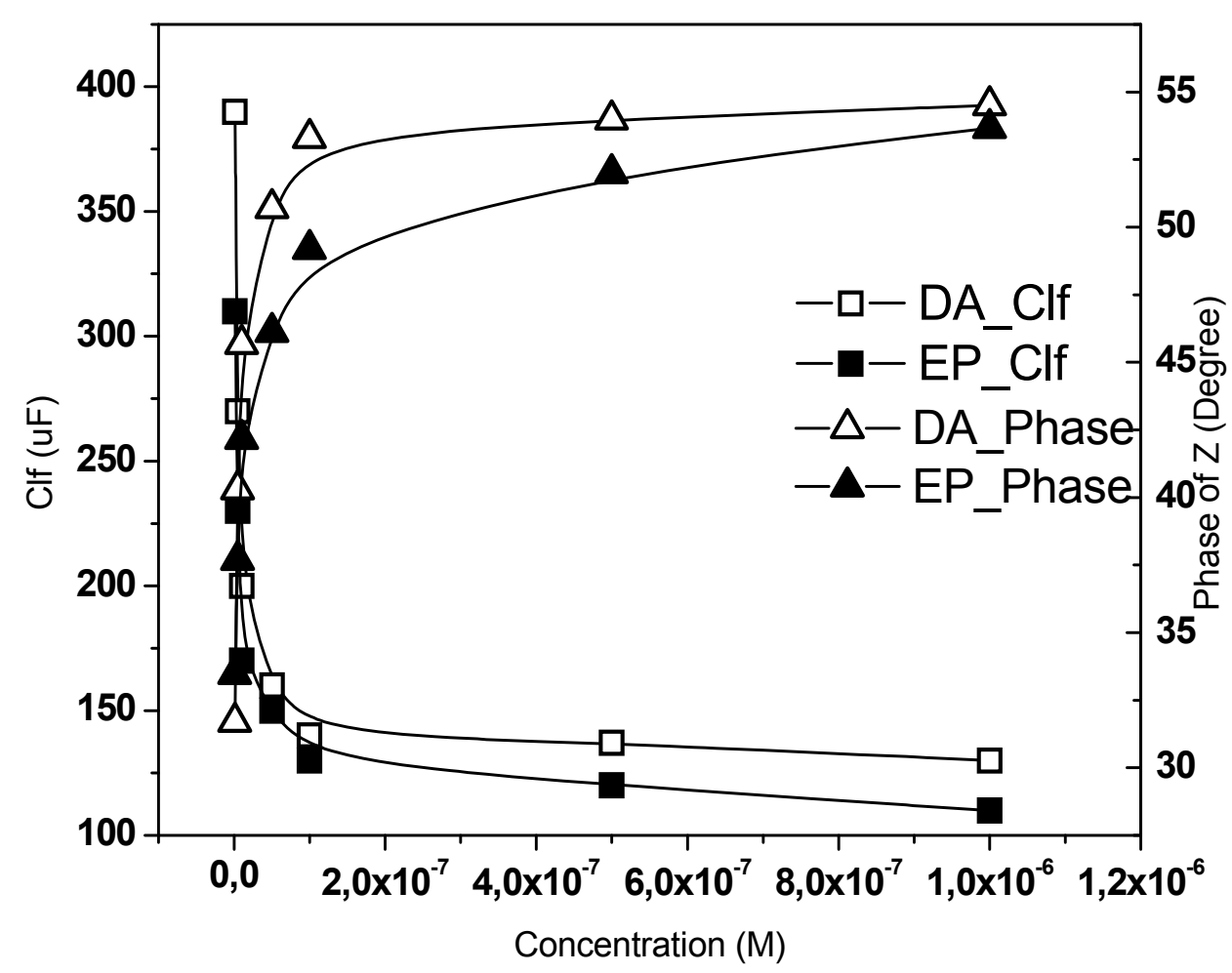

Figure 10. Graphic for Poly(In) concentration- $\mathrm{C}_{\mathrm{lf}}-\mathrm{Phase}$ of $\mathrm{Z}$ for Both DA And EP.

For this system while the concentration was increased, $C_{L F}$ values were decreased phase angle values were increased. At low concentrations these increasing and decreasing were more explicit than that of at high concentrations. The blockage of the porosity on the surface must be responsible for this behavior. And the final oxidation products (epinephrinechrome) of EP would block the electrode surface when it is oxidized directly on electrode[2].

\section{Conclusion}

In this study, Pt electrodes with coated poly $(\mathrm{Cz})$ and poly(In) in different electrolyte solution by electropolymerization. $\mathrm{NaClO}_{4}-\mathrm{ACN}$ electrolyte solution was selected as suitable electrolyte solution, due to high capacitive behavior. The usage of EIS technique for the determination of DA or EP in presence of AA was investigated. For this reason, the measurement EIS of prepared polymer coated electrodes in suitable conditions was performed by immersed in different concentrations (from $10^{-9} \mathrm{M}$ to $10^{-6} \mathrm{M}$ ) of DA or EP in presence of $10-4 \mathrm{M}$ of $\mathrm{AA}$ at $\mathrm{pH} 7$.

For poly $(\mathrm{Cz})$ coated electrode, when the concentration of DA or EP was increased, Rct was increased but $\mathrm{C}_{\text {lf }}$ and Phase angle were decreased. But for EP determination the discrimination between of concentration was clearer than that for DA, especially at low concentrations.

For poly(In) coated electrode, while the concentration of DA and EP was increased, Rct and phase angle values were increased but $\mathrm{C}_{\text {lf }}$ values were decreased.

As result, it was found that $\operatorname{Poly}(\mathrm{Cz})$ coated electrode was more convenient biosensor for using in determination of EP by EIS method than Poly(In) and for DA determination. In addition, compared with the results obtained from this study, the methods demonstrated and 
conditions used here are simple, sensitive and reliable and could thus be reasonably envisaged to be useful for practical applications. The EIS method was able to use as the readout of Poly $(\mathrm{Cz})$ coated electrode as a biosensor for the determination of EP.

\section{References}

[1] Jaber, Mohamed, "Dopamine receptors and brain function."Neuropharmacology 35.11 (1996): 1503-1519.

[2] Hernandez, P., "Cyclic voltammetry determination of epinephrine with a carbon fiber ultramicroelectrode."Talanta 46.5 (1998): 985-991.

[3] Banks, William A., "Enhanced leptin transport across the blood-brain barrier by a1adrenergic agents."Brain research 899.1 (2001): 209-217.

[4] Peskind, Elaine R., "Cerebrospinal fluid epinephrine in Alzheimer's disease and normal aging.”Neuropsychopharmacology 19.6 (1998): 465-471.

[5] Hows, M.E., "High-performance liquid chromatography/tandem mass spectrometric assay for the simultaneous measurement of dopamine, norepinephrine, 5hydroxytryptamine and cocaine in biological samples.” J Neurosci Methods, 138(1-2), 123-32 (2004).

[6] Sorouraddin, M. H., "Spectrophotometric determination of some catecholamine drugs using sodium bismuthate."Journal of pharmaceutical and biomedical analysis 18.4 (1998): 877-881.

[7] Zhang, Liyao, "Determination of dopamine in single rat pheochromocytoma cell by capillary electrophoresis with amperometric detection."Journal of Chromatography B 792.2 (2003): 381-385.

[8] He, Maofang, and Xiaohui Zheng, "A highly sensitive and selective method for dopamine detection based on poly (folic acid) film modified electrode. "Journal of Molecular Liquids 173 (2012): 29-34.

[9] Wang, Ying, "Application of graphene-modified electrode for selective detection of dopamine. "Electrochemistry Communications 11.4 (2009): 889-892.

[10] Kim, Yang-Rae, "Electrochemical detection of dopamine in the presence of ascorbic acid using graphene modified electrodes. " Biosensors and Bioelectronics 25.10 (2010): 2366-2369.

[11] Adekunle, Abolanle S., "Electrochemical Response and Impedimetric Behaviour of Dopamine and Epinephrine at Platinum Electrode Modified with Carbon NanotubesGold Nanocomposite. "Int. J. Electrochem. Sci 6 (2011): 2826-2844.

[12] Li, Fenghua, "Synthesis of Pt/ionic liquid/graphene nanocomposite and its simultaneous determination of ascorbic acid and dopamine. "Talanta 81.3 (2010): 1063-1068.

[13] Sun, Chia-Liang, "The simultaneous electrochemical detection of ascorbic acid, dopamine, and uric acid using graphene/size-selected Pt nanocomposites. "Biosensors and Bioelectronics 26.8 (2011): 3450-3455.

[14] Ates, Murat, "A Study of the electrochemical behavior of poly [N-vinyl carbazole] formed on carbon-fiber microelectrodes and its response to dopamine." IEEE Sensors Journal 8.10 (2008): 1628-1639. 
[15] Ates, Murat, "Carbon fiber microelectrodes electrocoated with polycarbazole and poly (carbazole-co-p-tolylsulfonyl pyrrole) films for the detection of dopamine in presence of ascorbic acid. "Microchimica Acta 160.1-2 (2008): 247-251.

[16] Sezer, Esma, Özlem Yavuz, and A. Sezai Saraç., "N $\square$ Vinylcarbazole $\square$ Acrylamide Copolymer Electrodes Electrochemical Response to Dopamine." Journal of The Electrochemical Society 147.10 (2000): 3771-3774.

[17] Bott, Adrian W., "Electrochemical techniques for the characterization of redox polymers. " Current Separations 19.3 (2001): 71-75.

[18] Katz, Eugenii, and Itamar Willner, "Probing biomolecular interactions at conductive and semiconductive surfaces by impedance spectroscopy: routes to impedimetric immunosensors, DNA $\square$ sensors, and enzyme biosensors." Electroanalysis 15.11 (2003): 913-947.

[19] Guan, Jian-Guo, Yu-Qing Miao, and Qing-Jie Zhang, "Impedimetric biosensors. "Journal of bioscience and bioengineering 97.4 (2004): 219-226.

[20] Sezgintürk, Mustafa Kemal, "A new impedimetric biosensor utilizing vegf receptor-1 (flt-1): Early diagnosis of vascular endothelial growth factor in breast cancer. "Biosensors and Bioelectronics 26.10 (2011): 4032-4039.

[21] Liu, Shufeng, "Electrochemical DNA biosensor fabrication with hollow gold nanospheres modified electrode and its enhancement in DNA immobilization and hybridization. "Biosensors and Bioelectronics 25.7 (2010): 1640-1645.

[22] Zhu, Ningning, "Sensitive impedimetric DNA biosensor with poly (amidoamine) dendrimer covalently attached onto carbon nanotube electronic transducers as the tether for surface confinement of probe DNA." Biosensors and Bioelectronics 25.6 (2010): 1498-1503.

[23] Macdonald, Digby D., "Reflections on the history of electrochemical impedance spectroscopy." Electrochimica Acta 51.8 (2006): 1376-1388..

[24] Dolas, Hacer, and A. Sezai Sarac, "An impedance-morphology study on poly (3methylthiophene) coated electrode obtained in boron trifluoride diethyl etherateacetonitrile." Synthetic Metals 195 (2014): 44-53.

[25] Dolas, Hacer, and A. Sezai Sarac, "Electrosynthesis of Poly (3-dodecyl thiophene) in Acetonitrile with Boron Trifluoride Diethyl Etherate: The Effect of the Electrolyte on Electrochemical Impedance and Morphology." Journal of The Electrochemical Society 159.1 (2011): 1-8.

[26] Dolas, Hacer, Esma Sezer, and A. Sezai Sarac, "Synthesis, Characterization and Electrochemical Polymerization of a Comonomer Bearing Thiophene and Imidazole: The Comparison of Impedance Behavior on Different Surfaces.” ECS Journal of Solid State Science and Technology 5.5 (2016): 211-217. 